\title{
Modeling and Application of a Modified Attributional Psychometric Instrument in Information Technology
}

\author{
Odoh. M, Mbeledogu. N, Okonkwor. R.
}

\begin{abstract}
Approximately three hundred stratified IT- Information Technology managers and professionals from selected industries, government agencies, colleges and universities completed a Modified Attributional Style Questionnaire - MASQ. This instrument was aimed specifically at examining attributions for work related events especially in IT. Respectively, a well-known validated measure of job satisfaction and intrinsic motivation was completed. The MASQ was shown to have satisfactory internal reliability. Attributions for positive events rather than negative were significantly correlated with demographic variables like occupational status and salary, but also job satisfaction and motivation. This study supports the previous work to the effect that an optimistic internal attribution is associated with satisfaction and motivation.

Keywords: Attribution, attribution styles, internal attribution, dimensions of attribution, foreseeability.
\end{abstract}

\section{Introduction}

Researchers of attribution [1] found that both failure and success activate emotional responses that, in turn, trigger an attributional process that impacts the outcome of an event. Sillars [2] noted that people tend to attribute negative effects to others rather than themselves, a pattern of behavior that was even more frequent in a stressful situation. Similarly, [3]; [4] found that people have the tendency to attribute failure to external causes and success to themselves [5]; [1]. In real-life organizational settings, a number of moderator variables influence the leader's attribution, and the response is constrained by those moderator variables as well as by boundary conditions, such as organizational norms and policies, and decision rules. Boehm (1983) indicated that data conversion projects require more discipline and stricter adherence to procedures.

The majority of the initial research on attribution theory focused on the perspective of the actor, and was mostly structured in the form of laboratory experiments [6]. Early research [6]; [7], [8]; [9]; [10], identified a causal dimension in attribution: locus of control. [9] categorized internal attribution as: ability, efforts and motivation, and external attribution: task difficulty, chance or luck.

A number of studies [8]; [11]; [9]; [12]; [13]; [14] following [15] model examined the circumstances under which different attributions were liable to be made. [16] noted two most influential articles that have provided a reasonable summary of most research on attributions: differences in perceptual focusing or visual perspective, differences in psychological perspective, and differences. [17] pointed out that most data conversion management strategies have not been treated with rigor in many IS publications. In addition, other IS literature has indicated that little evidence exists of the major conversion problems unleashed during migration of data [18]; [19]; [20]; [21]; [22]; [5]; [23]. According to [17], though, systems conversion takes place at the tail end of the systems development life cycle, its effective management is extremely important for the long-term survival and success of a system. The choice of a conversion strategy from the current information technology environment to a new environment is not easy, as is evident from other IT literature.

\section{Review of the related work}

Several studies are cited here that reflect implicit assumptions about differences between perceived causes of attributional judgment. [24] explained that the simplest and most influential analysis of the perceived causes of success and failure is presented as part of social learning theory. According to this theory, if a person receives reinforcement, he/she will make one of two causal attributions: a) the reinforcement was caused by something about himself.

\section{1. $\quad$ Lack of research}

There have been substantially more data conversion implementations and recommended methodologies than research-based investigations [25]. This may explain the lack of scholarly research publications pertaining to managing data conversion projects. [17] noted that comprehensive implementation management has not been treated with rigor in most IS (Information Systems) publications. In summary, they indicated that information systems literature has not addressed critical issues towards managing successful implementation. Following this observation, [21]noted that the implicit assumption appears to be that project team managers will be willing, the end user receptive, and the organization easily adaptive to the changing IT environment. Nonetheless, his further probe proved unrealistic. [25] Asserted that data conversion is a complex problem 
requiring more of our attention than it has received in the past. They further noted that relatively little work has been done to find a solution to make data conversion easier. In conclusion, they believe that conversion is done infrequently because of its complexity, but, will take place frequently when better techniques are known, automatic or semi-automatic aids are available, and when greater data independence is achieved.

[26] indicated that both information systems - IS researchers and practitioners have come to view implementation primarily as a process of organizational change and learning. However, if this notion is accepted, then the question will be how does the organization maintain a good strategy and at the same time, achieve a successful implementation? [27] recommended the following: 1) view implementation as starting from the beginning of development process, and 2) understand that the implementation success is greatly influenced by: methodologies, strategies and techniques. [28] argued that conversion is a research and business issue, and that there are few generally accepted approaches to conversion. They pointed out that the few successful migration-like projects reported in the literature only described ad hoc solutions to conversion problems. As a recommendation, they advised that management and users should undertake an intensive study to find the most appropriate approach for solving potential conversion problems. In conclusion, they indicated that data conversion management has received scant attention in the research community until recently.

[21] in his theory of systems evolution, conceptualized that most computer-based systems experience slow and superficial changes from their inception to their disappearance. He theorized that the life cycle of a system at some point may be affected by factors external in the manner that the system cannot accommodate, thus producing change. He further developed a maxim to his credit:

a) No matter how good the technology, it has little chance of success if business conditions do not foster its introduction

b) No matter how good the technology, if people do not want it, it will not work.

[21]) further argued that the core of this simple maxim has been forgotten, especially in the rush to new information technology. [29] found that in most organizational settings, senior managers are usually reluctant to disclose sensitive information regarding impact of change, adherence to procedures, employee turnover, and their attribution leadership model. They also noted that employees might not want to disclose management weaknesses due to job security, and organizational culture may pose serious threats to disclosure of critical information. [30] observed that software is increasingly turning into a commodity; thus, people increasingly expect systems that are customized to their needs. The author further noted that this situation is forcing nearly every software development organization to develop multiple variants of their systems to serve the specific needs of different customers or market segments. His conclusion indicated that many, if not most, software development organizations are finding that they need to build families of systems or product lines.

\section{Specific Procedures}

The sample consisted of approximately 300 stratified IT managers and professionals from selected industries. Participating organizations were limited to those who have undergone conversion in the past three years. Among the participating institutions, industries and government agencies chosen, a random sample of IT managers and professionals were obtained from IS departments such as administrative programming, networking, testing, support, systems administration, security and systems programming.

The MASQ is a scale designed specifically for IT organizational issues. It was designed to assess how an individual makes causal attributions for work-related events with multi-dimensional measures. The questionnaire was based on the previous research conducted by [31] that revealed consistent links between an optimistic attributional style at work and motivation in different occupational groups. The measure consists of 10 items that present brief description of hypothetical situations which are commonly experienced. Five of the hypothetical situations describe positive outcomes and five describe negative outcomes and are presented in Table 1.

Positive outcomes

Table 1: Hypothetical events that are related to work settings

Imagine that you apply for promotion and get it

Imagine that you solve a major problem that has occurred at work

Imagine that you successfully lead a group project with a positive outcome

Imagine that you are voted as the most popular boss in your section

Imagine that you are given a special performance reward at work

Negative outcomes

Imagine that you are turned down at a job interview

Imagine that your boss always acts aggressively toward you

Imagine that you can't get all the work done that others expect of you

Imagine that you gave an important talk in front of your colleagues and they

react negatively

Imagine that a superior gives you a poor annual report. 
The questionnaire below is based on nine different scenarios that the individual is asked to imagine him or herself. Five questions on each of these eight scenarios make up the MASQ, and the individual is asked to rate their response on a scale of 0-6. The MASQ contains five scales labeled (i) Internality, (ii) Stability, (iii) Globality, (iv) Externality, and (v) Personal Control. The questionnaire takes about 20 minutes to complete and can be undertaken on an individual or group basis. The MASQ can be used in practical and theoretical applications. In occupational settings, it provides opportunities for recognizing potential in job applications due to the association found between attributional styles, motivation and estimated social consensus. In training programs, attribution-training techniques hold great potential for performance enhancement. In addition to the very valid occupational applications, this questionnaire has great potential to aid further research concerning attributional style and work-related events.

1. To what extent was the cause due to something about you?

Totally due to me $5 \quad 4 \quad 3 \quad 2 \quad 1 \quad 0 \quad$ Not all due to me

2. In the future, at work, will this cause again influence what happens?

Will never again influence what $\quad \begin{array}{llllllll}6 & 5 & 4 & 3 & 2 & 1 & 0 & \text { Will always influence what happens }\end{array}$ happens

3. Is the cause something that just affects problem-solving or does it influence other areas of your life? Influence just this situation $\begin{array}{llllllll}6 & 5 & 4 & 3 & 2 & 1 & 0 & \text { Influences all areas of my life }\end{array}$

4. To what extent was cause something to do with other people or circumstances?

Totally due to other people or $\begin{array}{llllllll}6 & 5 & 4 & 3 & 2 & 1 & 0 & \text { Not at all due to other people or circumstances }\end{array}$ circumstances

5. To what extent was the cause due to chance?

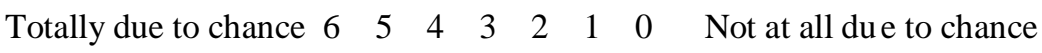

6. To what extent was the cause controllable by you?

Totally controllable by me $\begin{array}{llllllll}6 & 5 & 4 & 3 & 2 & 1 & 0 & \text { Not at al controllable by me }\end{array}$

7. To what extent was the cause controllable by your colleague?

Totally controllable by my $6 \begin{array}{lllllll}6 & 5 & 4 & 3 & 2 & 1 & 0\end{array}$ Not at all controllable colleagues bymy colleagues

8. To what extent do you think you could have foreseen the cause?

Totally foreseeable by me $\begin{array}{rllllll}6 & 5 & 4 & 3 & 2 & 1 & 0\end{array}$ Not at all foreseeable by me

9. How important would the situation be if it happened to you?

$\begin{array}{llllllll}\text { Not all important } & 6 & 5 & 4 & 3 & 2 & 1 & 0 \text { extremely important }\end{array}$

\section{Results and Discussion}

\subsection{Descriptive Statistical Analyses}

This section contains the results of the descriptive statistical analyses with tables that reflect the measure of central tendency and the dispersion of both dependent and independent variables [32]. The descriptive statistics computed for dependent variables (internality, stability, globality, externality and personal control) include.

(a) measure of central tendency (mean);

(b) variability (standard deviation);

(c) spread of the distribution (alpha).

Table 1 displays data for Chronbach's alpha including the mean, standard deviation and alpha for the five scales: internality, stability, globality, externality and personal control. The validity of the instrument used was previously established, and this section is intended to support the validity and reliability of this instrument. Cronbach's alpha reliability coefficient estimates the internal consistency of a set of items with a numerical range from .50 to .59 (poor), .60 to .69 (acceptable), $.70-.79$ (good), .80 to .89 (very good, and from .90 to .99 (excellent) (Isaac et al. 1995). Using the Chronbach's alpha test of the variables, a composite reliability coefficient of .71 was obtained. This means that the reliability as noted previously, exceeded the minimum criteria of .70. Subsequently, each of the dependent variables had alpha scores ranging from acceptable to good.

Table 2: Means, Standard Deviation and Alpha Scales for this study

\begin{tabular}{|l|l|l|l|l|l|l|}
\hline & \multicolumn{1}{l}{ POSITVE } & \multicolumn{3}{|c|}{ NEGATIVE } & \\
\hline Attributions & Means & SD & Alpha & Mean & SD & Alpha \\
\hline Internality & 4.60 & 2.50 & 0.72 & 2.32 & 1.10 & 0.72 \\
\hline Stability & 4.32 & .79 & 0.73 & 2.54 & .96 & 0.72 \\
\hline Globality & 2.35 & 1.06 & 0.67 & 4.11 & 1.02 & 0.69 \\
\hline Externality & 2.34 & 1.12 & 0.67 & 2.06 & .84 & 0.69 \\
\hline Personal control & 2.37 & 1.10 & 0.69 & 2.13 & .85 & 0.69 \\
\hline
\end{tabular}


The second reliability procedure was provided by the use of factor analysis. A VARIMAX rotation was implemented to improve the statistical interpretation. From the factor extraction, only the factors with eigenvalues greater than 1.0 were selected. The rotated and loaded factor matrix was evaluated with the following criteria. [33] indicated that a factor loading higher than .71 was considered excellent, .63 very good, 55 good, and 45 fair, and 32 poor. For the purposes of this study, only items with factor loading greater than .50 were considered statistically significant. A series of factor loadings and rotation were conducted with most items not satisfying the criteria dropped at appropriate stages. This process of repetition and elimination of items was continued until the factor solution satisfying the required criteria was obtained. The final factor solution yielded ten significant items; loading on three factors accounted for $77 \%$ of the positive attribution items, and $88 \%$ for the negative attribution.

Table 2 shows the rotated factors ranging from good to excellent, and from .50 being the minimum to .98 maximum factor score.

\begin{tabular}{|c|c|c|c|}
\hline & $\mathrm{F} \quad \mathrm{A} \quad \overline{\mathrm{C}}$ & $\mathrm{T} \quad \mathrm{O} \quad \mathrm{R}$ & \\
\hline & Internality & Externality & $\begin{array}{l}\text { Personal } \\
\text { control }\end{array}$ \\
\hline \multicolumn{4}{|l|}{ Positive } \\
\hline Internality & & & \\
\hline Stability & .79 & .90 & --- \\
\hline Globality & --- & --- & --- \\
\hline Externality & .78 & .84 & .55 \\
\hline Personal & --- & .69 & .50 \\
\hline control & .73 & .56 & .60 \\
\hline Eigenvalue & 0.75 & 2.68 & 1.94 \\
\hline \% Variance & 35.07 & 20.25 & 22.87 \\
\hline \multicolumn{4}{|l|}{ Negative } \\
\hline Internality & & & \\
\hline Stability & .79 & .90 & .55 \\
\hline Globality & .72 & .71 & .62 \\
\hline Externality & .74 & .78 & .52 \\
\hline Personal & .69 & .54 & .61 \\
\hline control & --- & .98 & .69 \\
\hline Eigenvalue & 2.34 & 2.01 & 1.34 \\
\hline$\%$ Variance & 46.76 & 20.17 & 16.68 \\
\hline
\end{tabular}

Note: Factor 1 = internality, Factor 2 = externality, Factor 3 = Personal control

Positive: Positive attribution styles based on the positive events

Negative: Negative attribution styles based on the negative events.

\subsection{Inferential Statistical Analysis}

To identify relationships between management attribution and attribution items: internality, externality, globality, stability and personal control, a Pearson correlation coefficient was performed. The purpose of any correlation study is to access the relationships between the variables. For the correlation table in Figure 7, only coefficients greater than or equal to .2500 were considered statistically significant relationships for this research [34]. A level of confidence of .05 was used in all statistical analyses. For this study, each of the five positive and five negative attribution items (dependent variables) and demographic (independent variables) were examined to assess the strength of the hypothesized relationships.

Attributional correlates of salary seem to be consistent: high salaries were positively correlated with personal control, externality and globality, but negatively correlated with positive internality and stability. These results suggest that explanatory style can predict reference in thought deficits in thought in work setting. Therefore, the null hypothesis was rejected with $95 \%$ confidence. The results of the factors and attribution style items considered significant are presented in Table 7. Significant correlation at .01 is flagged with two stars, and one star for correlation at the .05 significant levels. Statistically significant correlations were not found between the following independent variables: gender, age and education, and positive attribution styles: internality, stability, externality, globality and personal control. Position and salary were negatively correlated 
Modeling and Application of a Modified Attributional Psychometric Instrument in Information Technolog 5 with stability at the .023 significance level, and positively correlated with personal control at the .003 significance level.

Table 4. Correlations between demographic variables and attribution dimensions

Sex Age Education Occupational Salary

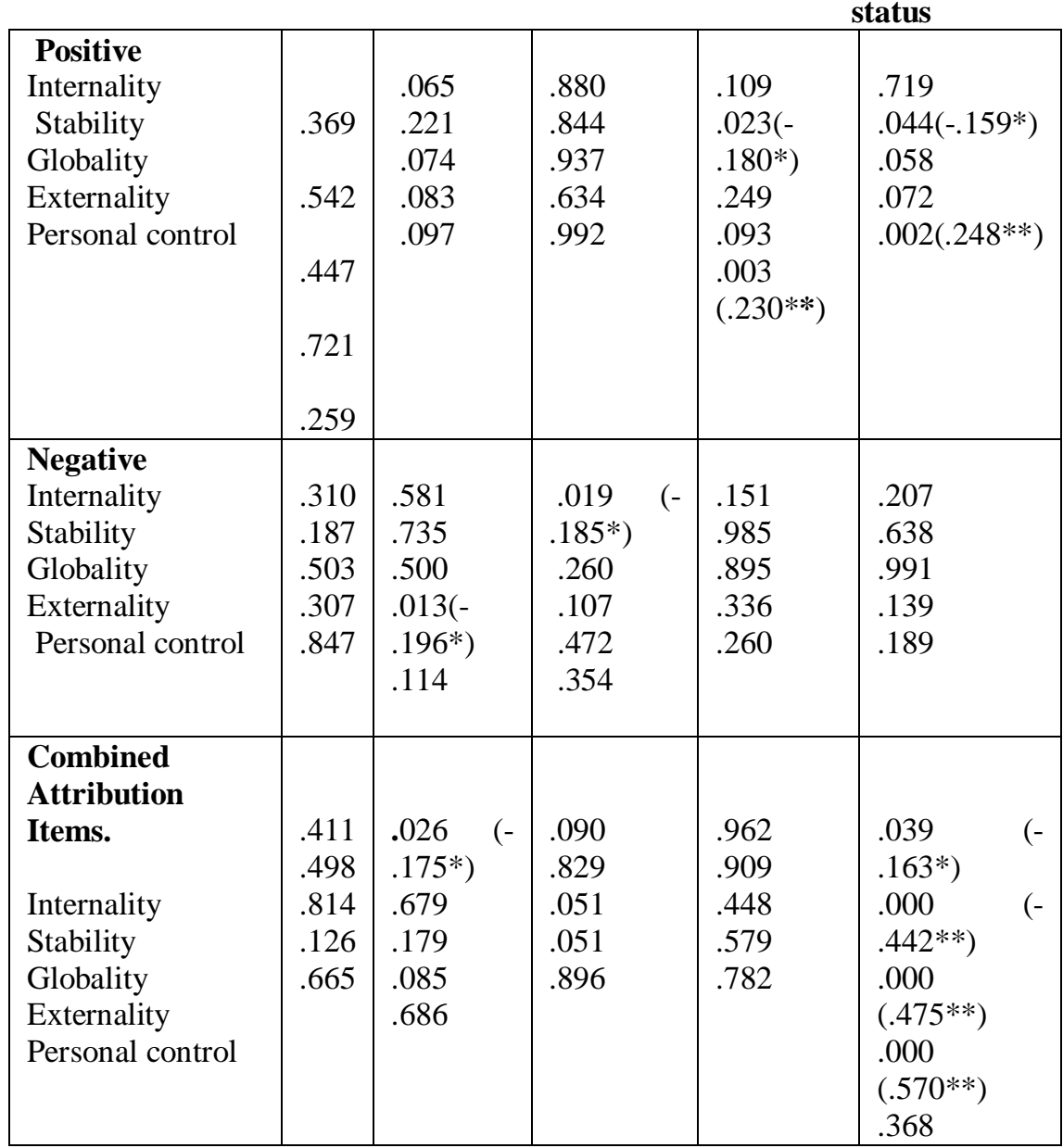

Note: $* *$ Correlation is significant at the .01 level (2-tailed)

* Correlation is significant at the .05 level (2-tailed)

The positive correlation between salary and position were consistent with what was proposed from the previous study [4]. Zuckerman found that high salary were positively correlated with internal, personal control and important judgments but negatively correlated with external, chance and superior control attribution. Education and age were negatively correlated at the .019 and .013 respectively between internality and externality from negative attribution style. Under the combined attribution style category, age was negatively correlated with internality at the .026 significant level, while salary was negatively correlated with internality and stability, and, positively correlated with globality and externality.

Table 5. Correlations for Attribution Styles, Factors and Attribution Items

Attribution Styles
Positive
Internality
Stability
Externality
Globality
Personal Control
Negative
Internality
Stability
Externality
Globality

$\begin{array}{lll}\text { Coefficients } & & \text { Alpha } \\ .184 * & & .019 \\ -.043 & & .584 \\ .853 * * & & .000 \\ .811^{* *} & & .000 \\ .678^{* *} & & .000 \\ .123 & \\ .627 * * & & .000 \\ .687 * * & & .000 \\ .667 * * & .000\end{array}$




$\begin{array}{lll}\text { Personal Control } & .491^{* *} & .000 \\ \text { Combined Attribution } & & \\ \text { Internality } & .013 & .867 \\ \text { Stability } & -.098 & .216 \\ \text { Externality } & .337^{* *} & .000 \\ \text { Table 6: (continued) } & & \\ \text { Globality } & .447^{* *} & .000 \\ \text { Personal Control } & .203^{* *} & .010\end{array}$

Note: $* *$ Correlation is significant at the .01 level (2-tailed)

* Correlation is significant at the .05 level (2-tailed)

The above correlation coefficients that resulted from the statistical analysis were used to evaluate each null hypothesis separately.

\section{Conclusions.}

Based on the findings reported in this study, the following conclusions are presen

Conclusion 1. It is concluded that optimistic attribution style of external, global and personal control is associated with good reference in thought that may lead to job and project success.

Conclusion 2. It is concluded that the association between attribution style (positive, negative and combined), and attribution items (internality, stability, externality, globality, and personal control) supports the need for IT professionals to attribute both failures and successes to internal and external rather than externals only.

Conclusion 3. It is concluded that there is both a positive and a negative relationship between project success and IT professionals' style of attribution. These attribution styles are very important as to the direction an IT professional may lead his/her subordinates.

Conclusion 4. It is concluded that management problems such as extended project time, high staff turnover, cost overrun, adherence to standard operating procedure (SOP), and user disagreement were the dominant reason for project failures. [35] suggested that the business impact of a failure is a key consideration in deciding whether or not to adopt a risk-reducing conversion strategy with its accompanying costs.

Conclusion 5. It is concluded that managerial decisions were the leading reason for data conversion project success or failures. [15] suggested that people naturally make attributions (judgments of, as well as responsibility and blame) along a number of quite specific dimensions.

Conclusion 6. It is concluded that pessimistic style predisposes people to poor performance, and poor performance is then triggered by failure in those individuals with predisposing style.

\section{Reference}

[1] Wong, P. T., \& Weiner, B. (1981). Why people ask "why" questions, and the heuristics of attributional search. Journal of Personality and Social Psychology, 40(1), 650-663.

[2] Gupta, S. (2011). Attribution Theory of Social Psychology. Downloaded 27 March 2012 from http://www.buzzle.com/articles/attribution-theory-of-social-psychology.html

[3] Silvester, J., Anderson, N. R., \& Patterson, F. (1999, March). Organizational culture change: An inter-group attributional analysis. Journal of Occupational Psychology, 7, 16-70.

[4] Zuckerman, M. (1979). The motivational basis is alive and well in attribution theory. Journal of Personality, 47(5), 245-287.

[5] Boehm, B. (1983). Software Cost Estimation: New Jersey: Prentice Hall.

[6] Phares, E. J. (1957). Expectancy changes in skill and chance situation. Journal of Abnormal Social Psychology, 54(1), 339-342.

[7] Feather, N. T. (1969). Attribution of responsibility and valence of success and failure in relation to internal confidence and task performance. Journal of Personality and Social Psychology, 13(1), 129-144.

[8] Feather, N. T., \& Simon, J. G. (1971). Causal attributions for success and failure in relation to expectations of success based on selective and manipulative control. Journal of Personality, 39(2), 527-541.

[9] Kukla, A. (1972). Attributional determinants of achievement related behavior. Journal of Personality and Social Psychology, 21(2), 166-174.

[10] Weiner, B., \& Kukla, A. (1970). An attributional analysis of achievement motivation. Journal of Personality and Social Psychology, 15(1), 1-20.

[11] Frieze, I., \& Weiner, B. (1971, February). Cue utilization and attributional judgments for success and failure. Journal of Personality, 39, 591-605

[12] Davis, W. L., \& Davis, D. E. (1972). Internal-external control and attribution of responsibility for success and failure. Journal of Personality, 40(1), 123-135.

[13] McMahan, I. D. (1973). Relationship between causal attribution and expectancy of success. Journal of Personality and Social Psychology, 28(1), 108-114.

[14] Kelley, J. H. (1972). Attribution theory in social psychology. Journal of Personality and Social Psychology, 20(1), 223-229.

[15 Weiner, B. (1985). An attributional theory of achievement motivation and emotion. Psychological Review, 92(2), 548-573.

[16] Jones, E. E. (1976). How do people perceive the causes of behavior? American Scientist, 64(1), 300-305.

[17] Shailendra, C. P., Efrem, G. M., \& Prashant, C. P. (1991, October). Strategies for converting from IT environment to another. Journal of Systems Management, 18, 23-27.

[18] Odoh, M. O. (2003). Data conversion: A study of Management issues in change process. PhD Dissertation,

[19] Lank, E. (1997, June). Leveraging invisible assets: The human factor. Long Range Planning, 30, 406-412 
[20] Ashworth, J. (2001). Excellence in support or support is more than a correct answer. Conference Proceedings of the ACMSIGUCCS, 1(1), 8-11.

[21] Barlow, F. J. (1990, July). Putting information systems planning methodologies into perspective. Journal of Systems Management, 14(1), 6-9.

[22] Bibble, D. M. \& Bostrom, R. (1987). Managing expert systems project: Factors critical for successful implementation. Conference Proceedings of the ACM, 4(1), 1-28.

[24] Spector, P. (1982). Behavior in organizations as a function of employees' locus of control. Psychological Bulletin, 91, $420-425$.

[25] Lum, V., Shu, N. C., \& Housel, B. C. (1976, September). A general methodology for data conversion and restructuring. IBM Journal of research and development, 5, 463-497.

[26] David, S., \& Mark, G. (1993, May). What's so Important about data conversion? Data conversion Laboratory, $13(1), 385$.

[27] Armour, P. G. (2002). The human factor in software development is the ingredient that ultimately gives project team its soul. Communications of the ACM, 45(1), 11-14.

[28] Bisbal, J., Lawless, D., Wu, B., \& Grimson, J. (1999). Legacy information systems: Issues and directions. Conference Proceedings of the IEEE (CS), 16(1), 21-28.

[29] Srivastava, B. N., \& Sett, P. K. (1998). Managerial attribution and response: an empirical study of an attributional leadership model in India. The Journal of Social Psychology, 138(5), 59-597.

[30] Verlage, M. (2002, July). The economic impact of product line adoption and evolution. IEEE Software, 7, 50-57

[31] Furnham, A. (1986, January). Economic locos of control. Human Relation, 39, 29-43.

[32] Norusis, M. J. (1991). SPSS/PC+ student software plus. Chicago: SPSS. Inc.

[33] Tabachnick, B., \& Fidell, L. S. (1989). Using multivariate statistics, (2nd edition). New York: Harper Collins.

[34] Gay, L. R. (1992). Educational research: Competencies for analysis and application. (4th ed.). New York: Merrill. 